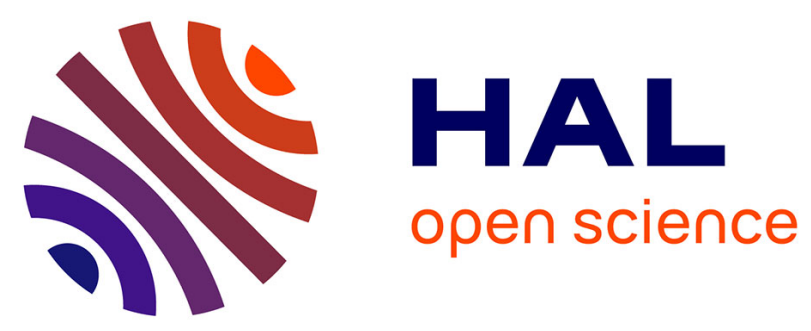

\title{
Periodic mesoporous organosilicas as porous matrix for heterogeneous lyophobic systems
}

Andrey Ryzhikov, T. Jean Jean Daou, Habiba Nouali, Joël Patarin, Judith

Ouwehand, Sander Clerick, Els de Canck, Pascal van Der Voort, Johan A

Martens

\section{To cite this version:}

Andrey Ryzhikov, T. Jean Jean Daou, Habiba Nouali, Joël Patarin, Judith Ouwehand, et al.. Periodic mesoporous organosilicas as porous matrix for heterogeneous lyophobic systems. Microporous and Mesoporous Materials, 2018, 260, pp.166-171. 10.1016/j.micromeso.2017.10.037 . hal-03544626

\section{HAL Id: hal-03544626 \\ https://hal.science/hal-03544626}

Submitted on 26 Jan 2022

HAL is a multi-disciplinary open access archive for the deposit and dissemination of scientific research documents, whether they are published or not. The documents may come from teaching and research institutions in France or abroad, or from public or private research centers.
L'archive ouverte pluridisciplinaire HAL, est destinée au dépôt et à la diffusion de documents scientifiques de niveau recherche, publiés ou non, émanant des établissements d'enseignement et de recherche français ou étrangers, des laboratoires publics ou privés. 


\title{
Periodic mesoporous organosilicas as porous matrix for heterogeneous
}

\section{lyophobic systems}

Andrey Ryzhikov ${ }^{\mathrm{a}^{*}}$, T. Jean Daou ${ }^{\mathrm{a}}$, Habiba Nouali ${ }^{\mathrm{a}}$, Joel Patarin ${ }^{\mathrm{a}^{*}}$, Judith Ouwehand ${ }^{\mathrm{b}}$, Sander Clerick $^{\mathrm{b}}$, Els De Canck ${ }^{\mathrm{b}}$, Pascal Van Der Voort ${ }^{\mathrm{b}}$, Johan A. Martens ${ }^{\mathrm{c}}$

${ }^{a}$ University of Haute-Alsace (UHA), Axe Matériaux à Porosité Contrôlée (MPC), Institut de Science des Matériaux de Mulhouse (IS2M), UMR 7361, Mulhouse, 68093, France.

${ }^{\mathrm{b}}$ Center for Ordered Materials, Organometallics and Catalysis (COMOC), Dep. of Inorganic and Physical Chemistry, Ghent University, Krijgslaan 281 - S3, 9000 Ghent, Belgium.

${ }^{\mathrm{c}}$ Center for Surface Chemistry and Catalysis, KU Leuven, Celestijnenlaan 200f - box 2461

3001 Leuven, Belgium,

\section{AUTHOR INFORMATION}

Corresponding Authors

Joël Patarin

*E-mail: joel.patarin@uha.fr Phone: +33 3893368 80. Fax: +33 389336885.

Andrey Ryzhikov

*E-mail: andrey.ryzhikov@uha.fr Phone: +33 3893367 54. Fax: +33 389336885.

\begin{abstract}
Periodic mesoporous organosilicas (PMO) have been studied for the first time as a porous matrix for heterogeneous lyophobic systems (HLS) for absorption and storage of mechanical energy by high pressure intrusion-extrusion of electrolyte solutions. It has been shown that the intrusion of $\mathrm{LiCl}$ aqueous solutions in ethane-bridged PMO material is irreversible that corresponds to a bumper behavior. The intrusion pressure increases strongly with the salt concentration - from $13 \mathrm{MPa}$ for 5 $\mathrm{M} \mathrm{LiCl}$ aqueous solution to $37 \mathrm{MPa}$ for $20 \mathrm{M}$ one. Such a pressure rise of 2.8 times is the highest observed for HLS based on mesoporous materials. Due to high intruded volume $(0.63-0.72 \mathrm{~mL} / \mathrm{g})$ specific absorbed energy achieves $27 \mathrm{~J} / \mathrm{g}$, which is close to the best values ever obtained for HLS based on zeosils and mesoporous silica. The characterization shows that after the intrusion-extrusion
\end{abstract}


experiments the ordered pore arrangement largely stays intact, but a slight increase of the mesopore volume is observed.

\section{KEYWORDS}

Periodic mesoporous organosilicas, high pressure intrusion-extrusion, heterogeneous lyophobic systems, electrolyte solutions 


\section{INTRODUCTION}

Heterogeneous lyophobic systems (HLS), which consist of a lyophobic porous matrix and a nonwetting liquid, are one of the promising technologies for absorption, storage and low temperature generation of mechanical energy [1-9]. The operating principle is the following: under compression, when the external pressure is equal or higher than capillary pressure, the liquid is intruded into the pores of the matrix with a large increase of the solid-liquid interface. Thus, the mechanical energy is transformed into interfacial energy. When the pressure reduces, the system can induce an expulsion of the liquid out of the pores (extrusion) with recovering of mechanical energy. Depending on the properties of porous material and the nature of nonwetting liquid, the HLS are able to absorb, dissipate or restore the supplied mechanical energy with a more or less significant hysteresis and, as a consequence, they display a bumper, shock-absorber or spring behavior, respectively.

First heterogeneous lyophobic systems developed by V. Eroshenko were based on porous silica and liquid metals [2], then on hydrophobized porous silicas and water as light and environmentally friendly nonwetting liquid [10,11]. Since water became the most used intruded liquid and its highpressure intrusion was studied for other types of hydrophobic materials such as pure silica zeolites [12-19] and metal-organic frameworks [20-23]. A use of electrolyte solutions was found to be an effective way to improve the energetic performances of HLS by a considerable increase of the intrusion pressure [24-30].

The HLS based on porous silicas demonstrate usually a shock-absorber or a bumper behavior with relatively low values of intrusion pressure (10-50 MPa), but their high intruded volume allows to achieve relatively high absorbed energy. Most part of the works on porous silicas concerns the materials with irregular nanopores of various form and diameter [10,11,28,31,32], but ordered mesoporous silicas with regular pore arrangement were also studied in several reports [33-38]. Nevertheless, a study of new types of hydrophobic porous materials with high pore volume is of considerable interest. 
Periodic Mesoporous Organosilicas or PMOs are hybrid nanomaterials which combine an inorganic stable silica matrix with versatile organic functionalities [39]. These organic functionalities are homogeneously distributed throughout the entire material. The synthesis of PMOs shows many similarities with the preparation of ordered mesoporous silicas such as MCMs and SBAs [40-42]. They are synthesized via the hydrolysis and subsequent polycondensation of a polysilsesquioxane around a structure-directing agent (SDA). The silane precursor is generally represented by (OR') ${ }_{3} \mathrm{Si}^{-}$ $\mathrm{R}-\mathrm{Si}(\mathrm{OR})_{3}$ with $\mathrm{R}$ the organic moiety and OR' a hydrolysable alkoxy function. The presence of the organic bridges can influence the chemical properties of the PMO, e.g., alter the hydrophobicityhydrophilicity. Currently, research on PMOs is performed for a broad range of applications: as heterogeneous catalysts, adsorbents for metal ions and volatile organic compounds, controlled drugs delivery systems and materials for electronics, however they have never been studied for applications in heterogeneous lyophobic systems.

In this work we present the study of high-pressure intrusion-extrusion of water and electrolyte solutions in an ethane-bridged PMO material with a thorough investigation on its structural and physicochemical properties. The organic moieties contained in the PMO material distinguishes it from the purely inorganic materials studied in the field so far. PMOs are known to be relatively hydrophobic and to have an increased mechanical and hydrolytic stability, compared to mesoporous silica materials $[43,44]$. These properties should be beneficial in their application as heterogeneous lyophobic systems.

\section{EXPERIMENTAL SECTION}

Reagents The reagent, Brij-76 (Polyoxyethylene (10) stearyl ether) was purchased from Sigma Aldrich, whereas, 1,2-bis(triethoxysilyl)ethane (97\%) and HMDS (hexamethyldisilazane, 98.5\%) were supplied from ABCR. $\mathrm{HCl}(37 \%)$ and chloroform (>99\%) were purchased from Carl Roth. All the reagents were used without further purifications.

\section{Synthesis of ethane PMO (PMO 76 ethane)}


The ethane-bridged PMO sample (hereafter, PMO 76 Ethane) was synthesized according to the following procedure, adapted from Fernandez and coworkers [45]. An amount of $6 \mathrm{~g}$ of Brij-76 surfactant was dissolved in a solution of $20 \mathrm{~mL} \mathrm{HCl}$ and $280 \mathrm{~mL}$ distilled water, followed by stirring at $50^{\circ} \mathrm{C}$ for $24 \mathrm{~h}$. After adding $19 \mathrm{~mL} \mathrm{1,2-bis(triethoxysilyl)ethane,} \mathrm{the} \mathrm{mixture} \mathrm{was} \mathrm{stirred} \mathrm{for} 24 \mathrm{~h}$ at the same temperature. The resulting gel was then aged at $90^{\circ} \mathrm{C}$ for $24 \mathrm{~h}$ under static conditions. A white powder was collected by filtration and thoroughly washed with distilled water. In order to remove the surfactant, $1 \mathrm{~g}$ of as-synthesized material was stirred in a solution of $1 \mathrm{~mL} \mathrm{HCl} \mathrm{in} 50 \mathrm{~mL}$ ethanol for $12 \mathrm{~h}$ at $80^{\circ} \mathrm{C}$. After repeating this process twice, the solid product was recovered by filtration, washed with ethanol and dried under vacuum at $120^{\circ} \mathrm{C}$.

\section{Hydrophobization with HMDS}

A total amount of $1 \mathrm{~g}$ of ethane $\mathrm{PMO}$, dried at $120^{\circ} \mathrm{C}$ under vacuum, was brought into a schlenk flask under argon atmosphere. $20 \mathrm{ml}$ of HMDS was added and the vial was closed. The mixture was stirred for six hours under argon atmosphere. Then, it was filtered and washed with chloroform. The white solid was stirred in chloroform overnight and filtered. The resulting powder was dried at $120^{\circ} \mathrm{C}$ under vacuum.

\section{Intrusion-Extrusion Experiments}

The intrusion-extrusion experiments of water and $\mathrm{LiCl}$ aqueous solutions in preliminary outgassed $\left(90^{\circ} \mathrm{C}, 6\right.$ hours under vacuum) PMO 76 Ethane sample were performed at room temperature using a modified mercury porosimeter (Micromeritics Model Autopore IV) as described in reference 13. The values of the intrusion $\left(\mathrm{P}_{\text {int }}\right)$ and extrusion $\left(\mathrm{P}_{\text {ext }}\right)$ pressures correspond to that of the half volume total variation. Pressure is expressed in Megapascals $(\mathrm{MPa})$ and volume variation in millilitres $(\mathrm{mL})$ per gram of calcined samples. The experimental error on the pressure and on the volume is estimated to be ca. $1 \%$.

After intrusion-extrusion experiments, the samples intruded with $\mathrm{LiCl}$ aqueous solution were filtrated and washed with water to remove traces of $\mathrm{LiCl}$. The absence of chloride in the filtrate was verified by adding few drops of $1 \mathrm{M}$ silver nitrate aqueous solution (no silver chloride precipitate was 
observed). Then the samples were dried at $70^{\circ} \mathrm{C}$ overnight and hydrated in a $80 \%$ relative humidity atmosphere for $24 \mathrm{~h}$ to restore the hydration state. For thermogravimetric experiments one part of the sample intruded with $20 \mathrm{M} \mathrm{LiCl}$ aqueous solution was not washed. After filtration, the solid was only dried at room temperature for 24 hours in order to avoid the extraction of the intruded solution from the pores. A similar treatment was performed on the water intruded sample.

\section{Powder X-ray Diffraction}

X-ray diffraction pattern of the different samples were recorded using a PANalytical MPD X'Pert Pro diffractometer operating with $\mathrm{Cu} \mathrm{K}_{\alpha}$ radiation $(\lambda=0.15418 \mathrm{~nm})$ in the $2 \theta$ degrees range $0.6-10$ and equipped with an $\mathrm{X}^{\prime}$ Celerator real-time multiple strip detector.

\section{Nitrogen Adsorption-Desorption Measurements}

Nitrogen adsorption-desorption isotherms were performed at $-196{ }^{\circ} \mathrm{C}$ using a Micromeritics ASAP 2420 apparatus. Prior to the adsorption measurements, the samples were outgassed at $90{ }^{\circ} \mathrm{C}$ under vacuum during 15 hours. Low outgassing temperature should allow to eliminate physisorbed water, but to avoid the dehydroxylation process. The specific surface area $\left(\mathrm{S}_{\mathrm{BET}}\right)$ and microporous volume $\left(\mathrm{V}_{\text {micro }}\right)$ were calculated using the BET and t-plot methods, respectively.

\section{Thermal Analysis}

Thermogravimetric (TG) analyses were carried out on a Mettler-Toledo TG/DSC Star System $^{\mathrm{e}}$ apparatus, under air flow, with a heating rate of $5^{\circ} \mathrm{C} / \mathrm{min}$ from 30 to $800{ }^{\circ} \mathrm{C}$.

\section{Solid-State NMR Spectroscopy.}

${ }^{29} \mathrm{Si}$ MAS (Magic Angle Spinning) and ${ }^{1} \mathrm{H}-{ }^{29} \mathrm{Si}$ CPMAS (Cross polarisation) NMR spectra were recorded at room temperature on a Bruker Advance II $300 \mathrm{MHz}$ spectrometer, with a double-channel $7 \mathrm{~mm}$ Bruker MAS probe. The recording conditions are given in Table 1.

Table 1: Recording conditions of the ${ }^{29} \mathrm{Si}$ MAS and ${ }^{1} \mathrm{H}-{ }^{29} \mathrm{Si}$ CPMAS NMR spectra. ${ }^{29} \mathrm{Si}$
MAS
CP MAS 


\begin{tabular}{lcc}
\hline Chemical shift standard & $\mathrm{TMS}^{\mathrm{a}}$ & $\mathrm{TMS}^{\mathrm{a}}$ \\
Frequency $(\mathrm{MHz})$ & 59.6 & 59.6 \\
Pulse width $(\mu \mathrm{s})$ & 1.87 & 4 \\
Flip angle & $\pi / 6$ & $\pi / 2$ \\
Contact time (ms) & $/$ & 1 \\
Recycle time (s) & 80 & $8^{\mathrm{b}}$ \\
Spinning rate (kHz) & 4 & 2500 \\
Scans number & 2500 & \\
${ }^{\mathrm{a}}$ TMS : TetraMethylSilane & & \\
${ }^{\mathrm{b}}$ The relaxation time T 1 was optimized & & \\
\hline
\end{tabular}

\section{RESULTS AND DISCUSSION \\ PMO synthesis}

The ethane PMO was synthesized by condensing the precursor (1,2-bis(triethoxysilyl)ethane) around a soft template (Brij 76) under acidic conditions. This synthesis resulted in a material with an ordered pore arrangement and narrow pore size distribution. The pore arrangement of this PMO is similar to that of ordered mesoporous silicas, such as MCM-41. However, the PMO material contains a high concentration of ethane units within the silica framework. This property makes the PMO more hydrophobic than pure silica. Even so, the PMO material still contains silanol groups. Thus, in order to render the PMO even more hydrophobic, the surface silanol groups were capped by grafting of a trimethylsilyl group. A schematic representation of the hydrophobized ethane PMO is shown in Scheme 1. A detailed characterization of the ethane PMO will be discussed in the following sections.

\section{Intrusion-extrusion study}

The intrusion-extrusion experiments with water and $\mathrm{LiCl}$ aqueous solutions were performed on PMO 76 Ethane sample. The corresponding curves (first intrusion-extrusion cycle and second intrusion 
curve) are shown in Figure 1. As shown in previous works, the volume variation observed at low pressure $(<5 \mathrm{MPa})$ corresponds to the compressibility of the particle bed and filling of its interparticular porosity $[20,46]$. The intrusion of water occurs at a quite low pressure (below $5 \mathrm{MPa}$ ). Therefore, from these low pressures and taken into account what is mentioned above, it is difficult to determine the behavior of this HLS system. However, according to the TG analysis (see below), all the liquid was expelled from the solid at atmospheric pressure. Therefore, the intrusion process seems to be reversible and occurs at very low pressures $(<3 \mathrm{MPa})$. Such a system seems to show a spring or better a shock-absorber behavior, but with very low energetic performances. For the others HLS (with 5, 10 and $20 \mathrm{M} \mathrm{LiCl}$ aqueous solutions) the intrusion steps are clearly observed at high pressures on the corresponding P-V diagrams. The inflexions observed on the extrusion curves at low pressure are probably related with the material flexibility, but the intrusion is irreversible and the «PMO 76 Ethane - $\mathrm{LiCl}$ aqueous solution» systems display a bumper behavior. Indeed, whatever the electrolyte concentration, the second intrusion curve is superimposable with the extrusion one of the $1^{\text {st }}$ cycle. Such a behavior will be confirmed by TG analysis. Therefore, as previously observed for HLS based on pure-silica zeolites [47,48], a change of the system behavior is observed between water and $\mathrm{LiCl}$ aqueous solutions. However, and surprisingly, for the PMO-based systems an evolution of the behavior in an opposite direction is observed: the intrusion becomes not reversible for $\mathrm{LiCl}$ aqueous solutions. According to the NMR results (see below), a less hydrophobic surface of the samples intruded with $\mathrm{LiCl}$ aqueous solutions might explain such a difference. The intrusion pressure values are close to 13,18 and $37 \mathrm{MPa}$ for 5,10 and $20 \mathrm{M} \mathrm{LiCl}$ aqueous solution, respectively. The increase of intrusion pressure with electrolyte concentration is a well-known phenomenon [26,28,30]. In HLS the intrusion pressure is generally determined by Laplace-Washburn equation: $P=2 \gamma \cos \theta / r$, where $\gamma$ - vapor-liquid surface tension, $r$-pore radius and $\theta$ - solid-liquid contact angle. Thus, the pressure rise can be explained by an increase of the surface tension and the contact angle with the $\mathrm{LiCl}$ concentration. It can be supposed that the rise of the contact angle is predominant in our case, since the surface tension increases only by $35 \%$ from pure water to $20 \mathrm{M} \mathrm{LiCl}$ aqueous solution $(72.8$ 
and $98 \mathrm{mN} / \mathrm{m}$, respectively [49]), whereas the pressure rises by 2.8 times from $5 \mathrm{M}$ to $20 \mathrm{M} \mathrm{LiCl}$ aqueous solutions. It should be also noticed that this increase of intrusion pressure is the most pronounced among all other reports on high pressure intrusion in mesoporous silicas.

The intrusion volume is about $0.7 \mathrm{~mL}$ per gram of $\mathrm{PMO}$ and increases with the $\mathrm{LiCl}$ concentration (0.63, 0.68 and $0.72 \mathrm{~mL} / \mathrm{g}$ for 5,10 and $20 \mathrm{M} \mathrm{LiCl}$, respectively). Due to the high intruded volume, the maximal value of absorbed energy achieves $27 \mathrm{~J} / \mathrm{g}$ that is close to the best values obtained for the systems based on pure silica zeolites [26,47] and higher than ones of the systems based on hydrophobized silica [33-38].

\section{X-ray diffraction}

The characterization of the PMO 76 Ethane sample by X-ray diffraction was performed before and after intrusion-extrusion experiments. The XRD patterns are reported in Figure 2 (only the $0.6-5^{\circ} 2 \theta$ range is shown since no peaks are observed for $2 \theta>5^{\circ}$ ). In all cases, three XRD peaks are clearly evidenced on the XRD patterns and indicate the (100) reflection and the second-order reflections (110) and (200). These well-resolved signals are indicative for a 2-D hexagonal pore ordering. For the intruded-extruded samples, only a very slight shift of the XRD peaks towards high angle values is observed. This indicates that the pore ordering is preserved after the intrusion-extrusion experiments. The mean hexagonal unit cell parameter (anex.) determined from these XRD patterns is ranging from $7.11 \mathrm{~nm}$ (nonintruded sample) to $7.01 \mathrm{~nm}(20 \mathrm{M} \mathrm{LiCl}$ intruded sample). Such a shift, in agreement with the $\mathrm{N}_{2}$ adsorption-desorption analysis, might be due to a slight compacting of the pore walls $(0.1 \mathrm{~nm})$ after intrusion-extrusion experiments.

\section{Thermogravimetric analysis}

The thermogravimetric curves of the PMO 76 Ethane sample before and after intrusion-extrusion with water and $20 \mathrm{M} \mathrm{LiCl}$ aqueous solution are given in Figure 3. For the nonintruded sample, two steps of weight loss are observed. The first one at low temperature $\left(30^{\circ}-150^{\circ} \mathrm{C}\right)$ is quite small $(0.8$ - 
1.2 wt.\%) and attributed to the desorption of physisorbed water molecules. The low value of this weight loss reveals the hydrophobic character of the PMO 76 Ethane material. The second step is more pronounced (weight loss $15.1 \mathrm{wt} . \%$ ) and starts at $260^{\circ} \mathrm{C}$. It corresponds to the decomposition of the PMO material, the oxidation of organic bridges and the dehydroxylation reactions. After only a drying step at room temperature, the TG curve of the water intruded sample is very similar to that of the nonintruded sample. Therefore, it can be concluded that water is completely expelled from the solid at atmospheric pressure revealing thus the reversible character of intrusion of this HLS system, which seems to show a spring or better a shock-absorber behavior. It is not the case of the intruded sample with $20 \mathrm{M} \mathrm{LiCl}$ aqueous solution after drying at room temperature, without washing. Its TG curve displays three main weight losses. The last one (14 wt.\%), observed in the temperature range $550-780^{\circ} \mathrm{C}$, might be attributed to the removal of chloride compounds. Indeed, the XRD pattern of the product after heating at $800^{\circ} \mathrm{C}$ (not reported) corresponds to a mixture of lithium silicates $\left(\mathrm{Li}_{2} \mathrm{SiO}_{3}\right.$ and $\mathrm{Li}_{2} \mathrm{Si}_{2} \mathrm{O}_{5}$ ) with traces of cristobalite indicating clearly that the silica of the PMO material reacted with $\mathrm{LiCl}$. Therefore, only the two first weight losses are characteristic of the intruded PMO 76 Ethane sample. The first weight loss, below $150^{\circ} \mathrm{C}$ and close to $45 \mathrm{wt} . \%$, corresponds to the removal of the water molecules arising from the intruded liquid and from those trapped in the interparticular porosity due to the low drying temperature. Such a weight loss, confirms the bumper behavior of the "PMO 76 Ethane-20M LiCl aqueous solution" system. The second weight loss ( 8 wt.\%) occurring between 220 and $520^{\circ} \mathrm{C}$ can be assigned to the degradation of the organic network of the PMO material. This weight loss, calculated for $100 \%$ of PMO 76 Ethane solid is similar to the one observed for the nonintruded sample (i.e., 15 wt.\%).

\section{$\mathbf{N}_{2}$ adsorption-desorption measurements}

It is worthy to note that for this characterization, the intruded samples were carefully washed with distilled water and dried at $70^{\circ} \mathrm{C}$ for 24 hours. $\mathrm{N}_{2}$ adsorption-desorption isotherms of the nonintruded sample and the intruded ones with $\mathrm{H}_{2} \mathrm{O}$ and $20 \mathrm{M} \mathrm{LiCl}$ aqueous solution are given in Figure 4. The 
isotherms are mainly of type IV with a H2(a) hysteresis, which according to UIPAC [50] can be attributed either to pore-blocking/percolation in a narrow range of pore necks or to cavitation-induced evaporation. The isotherms are almost superimposable up to $\mathrm{p} / \mathrm{p}_{0}=0.5$, but the samples intruded with water and $20 \mathrm{M} \mathrm{LiCl}$ aqueous solution show higher mesopore volume. BET surface area of the samples is close to $420 \mathrm{~m}^{2} / \mathrm{g}$ and the total pore volume is equal to $0.83 \mathrm{~mL} / \mathrm{g}$ for the nonintruded sample and $0.90 \mathrm{~mL} / \mathrm{g}$ for both intruded ones with a mesopore volume of 0.68 and $0.75 \mathrm{~mL} / \mathrm{g}$, respectively. The increase of pore volume for the intruded samples can be related with a partial breaking of siloxane bridges (see NMR results) after intrusion-extrusion experiments. It can be also hypothesized that in the nonintruded sample mesopores are partially obstructed by the HMDS molecules less or more strongly grafted on the surface after hydrophobization and these molecules would be eliminated during the intrusion at high pressure. Such a hypothesis seems to be also confirmed by NMR spectroscopy. The pore diameter (BdB) ranges between 4.2 to $5.1 \mathrm{~nm}$ with an average value of $4.5 \mathrm{~nm}$. This average value is the same for all the samples. Therefore, the slight decrease of the unit cell parameter observed by XRD $(0.1 \mathrm{~nm})$ is therefore probably due to a compacting of the pore walls of the PMO material.

\section{NMR spectroscopy}

Also here the intruded samples were carefully washed with distilled water and dried at $70^{\circ} \mathrm{C}$ for 24 hours. The ${ }^{29}$ Si MAS NMR spectra of PMO 76 Ethane samples before and after intrusion-extrusion experiments with $20 \mathrm{M} \mathrm{LiCl}$ aqueous solution are shown in Figure 5. The spectrum of the nonintruded sample exhibits three main resonances at 9, -58 and $-65 \mathrm{ppm}$ and a broad one at $-46 \mathrm{ppm}$. The resonances at $-46,-58$ and -65 ppm can be assigned to Si species covalently bounded to carbon atoms: $\mathrm{T}_{1}\left[\mathrm{C}-\mathrm{Si}(\mathrm{OH})_{2}(\mathrm{OSi})\right], \mathrm{T}_{2}\left[\mathrm{C}-\mathrm{Si}(\mathrm{OH})(\mathrm{OSi})_{2}\right]$ and $\mathrm{T}_{3}\left[\mathrm{C}-\mathrm{Si}(\mathrm{OSi})_{3}\right]$ sites, respectively [51-55]. The observation of these T sites in the ${ }^{29} \mathrm{Si}$ MAS NMR spectrum confirms the presence of the $-\mathrm{CH}_{2}-\mathrm{CH}_{2}$ moieties in the framework. A slight increase of $\mathrm{T}_{1}$ and $\mathrm{T}_{2}$ signals confirmed on the ${ }^{1} \mathrm{H}-{ }^{29} \mathrm{Si} \mathrm{CP}$ MAS NMR spectra (Figure 6) is observed for the intruded sample. It can be ascribed to the formation of 
silanol defects under $20 \mathrm{M} \mathrm{LiCl}$ intrusion arising from the breaking of siloxane bridges. Furthermore, the absence of any other signal for the $\mathrm{Q}^{\mathrm{n}}\left[\mathrm{Si}-(\mathrm{OSi})_{\mathrm{n}}(\mathrm{OH})_{4-\mathrm{n}}\right]$ species between -90 and $-120 \mathrm{ppm}$ confirms that practically no silicon-carbon bond was cleaved either during the synthesis or after intrusion-extrusion experiments. The resonance at $9 \mathrm{ppm}$ corresponds to silicon from the trimethyl silyl function, which was used to cap the silanol groups. In the intruded sample, on the MAS spectrum the area of this component is slightly lower than the one of the nonintruded sample indicating, in agreement with the $\mathrm{N}_{2}$ physisorption results, the presence of a slightly lower amount of trimethyl silyl functions in the intruded PMO material. From these NMR data, we can conclude that the PMO material largely stays intact, even after the high pressure treatment with a $20 \mathrm{M} \mathrm{LiCl}$ solution. This, together with the XRD and nitrogen sorption data, confirms the high structural stability of the ethane PMO.

\section{CONCLUSION}

In this work an ethane bridged periodic mesoporous organosilica has been studied for the first time as a porous matrix for heterogeneous lyophobic systems which can be used for absorption and storage of mechanical energy. High pressure intrusion-extrusion experiments with electrolyte solutions have shown that " PMO 76 Ethane - $\mathrm{LiCl}$ aqueous solution" systems demonstrate a bumper behavior with an irreversible intrusion. The intrusion pressure increases with the salt concentration from 13 to 37 $\mathrm{MPa}$ for 5 and $20 \mathrm{M} \mathrm{LiCl}$ aqueous solutions, respectively. This pressure rise of 2.8 times with salt concentration is the highest observed for the HLS based on mesoporous materials and should be mostly related with the increase of solid-liquid contact angle. An increase of intruded volume from 0.63 to $0.72 \mathrm{~mL} / \mathrm{g}$ for 5 and $20 \mathrm{M} \mathrm{LiCl}$ aqueous solutions, respectively, has been also observed. Due to the high intruded volume, the maximal value of absorbed energy achieves $27 \mathrm{~J} / \mathrm{g}$, which is close to the best values obtained for the systems based on pure silica zeolites and higher than for ones based on hydrophobized silica. With water, as nonwetting liquid, the intrusion occurs at low pressure but 
all the liquid is expelled from the solid at the pressure close to atmospheric one. The corresponding HLS system seems to behave as a spring or better a shock-absorber.

Characterization of the ethane PMO shows that the ordered pore arrangement largely stays intact after the intrusion-extrusion experiments, proving the mechanical stability of the sample. However, the slight increase of the mesopore volume for the intruded samples can be due to the breaking of some siloxane bonds. Another explanation can be the slight decrease of the amount of grafted HMDS molecules in the PMO material after intrusion under high pressure. Consequently, this decrease leads to a less hydrophobic surface which could explain the bumper behavior observed for the "PMO 76 Ethane- $\mathrm{LiCl}$ aqueous solution" systems. With the high absorbed energy value, we have shown for the first time that PMO materials are indeed very interesting materials for heterogeneous lyophobic systems.

\section{ACKNOWLEDGEMENTS}

JAM acknowledges the Flemish Government for long-term structural funding (Methusalem)

\section{REFERENCES}

[1] V. A. Eroshenko, Int. Patent WO96/18040, 1996.

[2] V. A. Eroshenko, URSS Patent 1333870, 1985.

[3] V. A. Eroshenko, A. Popyk, Int. J. Thermodyn. (IJoT) 17 (2014) 33-41.

[4] L. Coiffard, V.A. Eroshenko, J.P.E. Grolier, AIChE Journal 51 (2005) 1246-1257.

[5] A. Laouir, L. Luo, D. Tondeur, T. Cachot, P. Le Goff, AIChE Journal 49 (2003) 764-781.

[6] V. A. Eroshenko, I. Piatiletov, L. Coiffard, V.P. Stoudenets, J. Proc. Mech. Eng., Part D: J. Automob. Engg. 221 (2007) 301-312.

[7] V. A. Eroshenko, J. Proc. Mech. Eng., Part D: J. Automob. Engg. 221 (2007) 285-300.

[8] T. Iwatsubo, C.V. Suciu, K. Yaguchi, M. Ikenaga, J. Coll. Inter. Sci. 283 (2005) 196-214.

[9] C. V. Suciu, K. Yaguchi, Experimental Mechanics. 49 (2009) 383-393. 
[10] V.A. Eroshenko, A. Y. Fadeev, Colloid Journal (Translation of Kolloidnyi Zhurnal) 57(4) (1995) 446-449.

[11] A. Y. Fadeev, V.A. Eroshenko, J. Coll. Inter. Sci. 187 (1997) 275-282.

[12] V.A. Eroshenko, R.C. Regis, M. Soulard, J. Patarin, J. Am. Chem. Soc. 123 (2001) 8129-8130.

[13] M. Trzpit, M. Soulard, J. Patarin, Chem. Lett. 36 (2007) 980-981.

[14] L. Tzanis, M. Trzpit, M. Soulard, J. Patarin, Microporous Mesoporous Mater. 146 (2011) 119126.

[15] M. A. Saada, S. Rigolet, J. L. Paillaud, N. Bats, M. Soulard, J. Patarin, J. Phys. Chem. C 114 (2010) 11650-11658.

[16] O. V. Ievtushenko, V. A. Eroshenko, Y. Grosu, J. M. Nedelec, J. P. E Grolier, Phys. Chem. Chem. Phys. 15 (2013) 4451-4457.

[17] L. Tzanis, M. Trzpit, M. Soulard, J. Patarin, J. Phys. Chem. C 116 (2012) 20389-20395.

[18] I. Khay, L. Tzanis, T. J. Daou, H. Nouali, A. Ryzhikov, J. Patarin, Phys. Chem. Chem. Phys. 15 (2013) 20320-20325.

[19] A. Ryzhikov, I. Khay, H. Nouali, T. J. Daou, J. Patarin. RSC Adv. 4 (2014) 37655-37661.

[20] G. Ortiz, H. Nouali, C. Marichal, G. Chaplais, J. Patarin, Phys. Chem. Chem. Phys. 15 (2013) 4888-4891.

[21] I. Khay, G. Chaplais, H. Nouali, G. Ortiz, C. Marichal, J. Patarin, Dalton Trans. 45 (2016) 4392-4400.

[22] Y. Grosu, M. Li, Y. L. Peng, D. Luo, D. Li, A. Faik, J. M. Nedelec, J. P. E. Grolier, ChemPhysChem 17 (2016) 1-7.

[23] Y. Grosu, G. Renaudin, V. A. Eroshenko, J. M. Nedelec, J. P. E. Grolier, Nanoscale 7 (2015) 8803-8810.

[24] M. Soulard, J. Patarin, French Patent FR2976030, 2011.

[25] L. Tzanis, H. Nouali, T. J. Daou, M. Soulard, J. Patarin, Mater. Lett. 115 (2014) 229-232. 
[26] I. Khay, T. J. Daou, H. Nouali, A. Ryzhikov, S. Rigolet, J. Patarin, J. Phys. Chem. C 118 (2014) 3935-3941.

[27] A. Han, Y. Qiao, J. Mater. Res. 22 (2007) 644-648.

[28] B. S. Falgun, Y. Qiao, J. Appl. Phys. 100 (2006) 034311/1-4.

[29] G. Ortiz, H. Nouali, C. Marichal, G. Chaplais, J. Patarin, J. Phys. Chem. C 118 (2014), 73217328.

[30] M. Michelin-Jamois, C. Picard, G. Vigier, E. Charlaix, Phys. Rev. Lett. 115 (2015) 036101/14.

[31] B. Falgun, F. B. Surani, X. Kong, Y. Qiao, Appl. Phys. Lett. 87 (2005) 251906/1-3.

[32] F. Gomez, R. Denoyel, J. Rouquerol, Langmuir 16 (2000) 4374-4379.

[33] T. Martin, B. Lefevre, D. Brunel, A. Galarneau, F. Di Renzo, F. Fajula, P. F. Gobin, J. Quinson, G. Vigier, Chem. Comm. 1 (2002) 24-25.

[34] B. Lefevre, A. Saugey, J. L. Barrat, L. Bocquet, E. Charlaix, P. F. Gobin, G. Vigier, J. Chem. Phys. 120 (2004) 4927-38.

[35] L. Guillemot, A. Galarneau, G. Vigier, T. Abensur, E. Charlaix, Rev. Sci. Instrum. 83 (2012) 105105/1-4.

[36] A. Han, Y. Qiao, Chem. Phys. Lett. 454 (2008) 294-298.

[37] A. Han, W. Lu, V. K. Punyamurtula, T. Kim, Y. Qiao, J. Appl. Phys. 105 (2009) 024309/1-4.

[38] A. Han, V. K. Punyamurtula, Y. Qiao, Appl. Phys. Lett. 92 (2008) 153117/1-3.

[39] P. Van Der Voort, D. Esquivel, E. De Canck, F. Goethals, I. Van Driessche, F. J. RomeroSalguero, Chem. Society Reviews 42 (2013) 3913-3955.

[40] D. J. S. Beck, J. C. Vartuli, W. J. Roth, M.E. Leonowicz, C. T. Kresge, K. D. Schmitt, C. T. W. Chu, D. H. Olson, E. W. Sheppard, S. B. McCullen, J. B. Higgins, J. L. Schlenker, J. Am. Chem. Soc. 114 (1992) 10834-10843.

[41] D. Y. Zhao, J. L. Feng, Q. S. Huo, N. Melosh, G. H. Fredrickson, B. F. Chmelka, G. D. Stucky, Science 279 (1998) 548-552. 
[42] D. Y. Zhao, Q. S. Huo, J. L. Feng, B. F. Chmelka, G. D. Stucky, J. Am. Chem. Soc. 120 (1998) 6024-6036.

[43] G. Smeulders, V. Meynen, A. Silvestre-Albero, K. Houthoofd, M. Mertens, J. Silvestre-Albero, J. A. Martens, P. Cool, Materials Chemistry and Physics 132 (2012) 1077-1088.

[44] F. Goethals, C. Vercaemst, V. Cloet, S. Hoste, P. Van Der Voort, I. Van Driessche, Microporous Mesoporous Mater. 131 (2010) 68-74.

[45] R. Otero, D. Esquivel, M. A. Ulibarri, C. Jiménez-Sanchidrián, F. J. Romero-Salguero, F. J. M. Fernández, Chemical Engineering Journal 228 (2013) 205-213.

[46] G. Ortiz, H. Nouali, C. Marichal, G. Chaplais, J. Patarin, J. Phys. Chem. C 118 (2014) 2131612322.

[47] A. Ryzhikov, L. Ronchi, H. Nouali, T. J. Daou, J. L. Paillaud, J. Patarin, J. Phys. Chem. C 119 (2015) 28319-25.

[48] A. Ryzhikov, I. Khay, H. Nouali, T. J. Daou, J. Patarin, Phys. Chem. Chem. Phys. 16 (2014) 17893-17899.

[49] P. Wang, A. Anderko, R. D. Young, Ind. Eng. Chem. Res. 50 (2011) 4086-4098 and refs. wherein.

[50] M. Thommes, K. Kaneko, A. V. Neimark, J. P. Olivier, F. R. Reinoso, J. Rouquerol, S.Sing, Pure Appl. Chem. 87 (2015) 1051-1069.

[51] X. Y. Bao, X. Li, X. H. Zhao, J. Phys. Chem. B 110 (2006) 2656-2661.

[52] M. C. Burleigh, S. Jayasundera, C. W. Thomas, M. S. Spector, M. A. Markowitz, B. P. Gaber, Colloid Polym. Sci. 282 (2004) 728-733.

[53] Z. Zhang, X. Yan, B. Tian, S. Shen, D. Chen, G. Zhu, S. Qiu, D. Zhao, Chem. Lett. 34 (2005) $182-183$.

[54] Y. Pan, H. Wu, G. L. Jheng, H. G. Tsai, K. Kao, J. Phys. Chem. C 113 (2009) 2690-2698.

[55] E. Cho, M. Kim, M. Jaroniec, J. Phys. Chem. C 112 (2008) 4897-4902. 